\title{
Destination Image Perception of Tourists to Guangzhou-Based on Content Analysis of Online Travels
}

\author{
Xiaohong Li \\ School of Management, Jinan University, Guangzhou, China \\ Email: 382796681@qq.com
}

Received 19 August 2015; accepted 27 September 2015; published 30 September 2015

Copyright (C) 2015 by author and Scientific Research Publishing Inc.

This work is licensed under the Creative Commons Attribution International License (CC BY). http://creativecommons.org/licenses/by/4.0/

(c) (i) Open Access

\begin{abstract}
It is said that Guangzhou is an indefinable city. This paper analyzed the online travels from www.mafengwo.cn to study the destination image perception of tourists to Guangzhou. Content analysis was used to investigate the destination image perception of tourists from two aspects, namely cognitive image and affective image. Then by comparing the image of Guangzhou positioning in the literature with the online travels image, the paper concluded that Lingnan, Ram City and delicious food were more important in tourists' perception. The results can provide reference when the government promotes the Guangzhou destination image.
\end{abstract}

\section{Keywords}

Guangzhou, Destination Image, Online Travels, Content Analysis

\section{Introduction}

It is said that Guangzhou is an indefinable city. There was a time that Guangzhou government used the image of Flower City, Business City and Lingnan Cultural City to advertise Guangzhou, but failed to get good results. In 2015, an advertising video called "Guangzhou was born because of you" was broadcast, it had caused extensive dispute. It was because that the video just displayed the modern city landscape, but neglected the characteristics of Guangzhou, such as Lingnan culture landscape. At the same time, from April 15, 2015, Southern Metropolis Daily made series report: How to develop tourism, offer advice and suggestions to make Guangzhou be a tourism city. As a result, different specialists from various perspectives expressed their opinions. A number of scholars studied the destination image of Guangzhou, however, most of them took qualitative research according the history of Guangzhou. Some of them came up with the strategies to promote Guangzhou image. While in the 
quantitative research, some scholars took empirical study to explore food cultural landscape of Guangzhou, and others studied the tourists' cognitive difference system. However, there is no qualitative research from tourists' perspective to study the destination image perception to Guangzhou.

In the era of internet developing rapidly, a large number of tourists publish their travel experience using words to record their tourism for other readers. These travels are not only the writers' experience, but also good study materials. Meanwhile these materials are free and easy to receive. In China, the places using these travels and blogs to study the destination image are Tibet, Beijing, Taiwan, and so on. Some of them using content analysis method just analyzed the high-frequency of the words, but haven't analyzed the sentences as well as the described paragraphs while some of them just analyzed the sentences and described paragraphs written by different writers. Some papers analyzed small amount of travels individually. Therefore, we think we can apply content analysis method to analyze the travels combines the high-frequency words with sentences and described paragraphs and use these materials to study Guangzhou destination image. As a result, this paper analyzed the travels about Guangzhou to investigate tourists’ destination image perception. The results of tourists' destination image perception can provide reference when the government promotes the Guangzhou destination image.

\section{Literature Review}

\subsection{Tourism Destination Image}

Tourism destination image has been studied in 1970s [1], the concept was given by Hunt in the early years, and he considered tourism destination image was someone's impression to his/her non-resident place, which was a pure subjective conception [2]. Crompton and Kotler (1979) pointed out that tourism destination image was a comprehensive of belief, opinion and impression that tourists to a place or destination [3]. Echtner and Ritchie summarized tourism destination image was a tourist's opinion to the whole destination and the whole characteristics, and based on it, they proposed a destination image framework, i.e. holistic-attribute, functional-psychological, common-unique [4]. The definitions of tourism destination image mentioned above are from the demand of tourists' perspective, they stressed from cognitive psychology and the perception of individual and community. On the other hand, some authors define tourism destination image from supply perspective. They distinguished two kinds of image, which were projected image and received image (Koteler and Barich, 1991) [5]. Projected image was regarded as people's opinion and impression to the destinations they paid close attention to, actually, it could be seen as a duplication of symbol and meaning, which was constructed and spread in society (Nuria and Jose, 2005) [6]. Received image was formed by projected information, tourists' desire, motivation and previous knowledge, experience, preference and other personality (Bramwell and Rawdig, 1996) [7]. Baloglu and McCleary tended to believe image was constituted by tourists' rational and emotional express, and they connected each other closely. On the one hand, perceptual/cognitive appraisal involved individual's brief and acquaintance, while affective appraisal involved the emotion to the destination or attaching to it. Academic community gets consensus on two points, namely cognitive appraisal is the fundament of affective appraisal, and affective appraisal derives from the cognition of objects [8]. Image of a destination is the result of cognitive appraisal and affective appraisal. Grosspietsch (2006) distinguished two kinds of tourism destination image, they were tourists' perceived image and destinations projected image, and tourists' perceived image were cognition and impression of potential and actual tourists to destinations. The latter one were tourism operators tended to set up the image in tourists' mind [9]. Some scholars divided tourism destination image according to the visiting time, which were original image and re-evaluation image (Selby and Nigel, 1996) [10].

From the definition of tourism destination image mentioned above, the general characters of them are listed as follows: Firstly, they stresses the perception of individual. Secondly, it is individual's cognition to one particular tourism destination. Finally, the perception isn't always the same as the reality of the destination, which exists subjectivity.

In China, the study of tourism destination image began in 1980s, and it became study hotspot in 1990s. Qiu's article, Analysis the Tourism Image of China, was considered the earliest paper to study destination image in China [11]. Li (1999) has written a book called Tourism Destination Image Planning: Theory and Practice is the first book to discuss destination image systematically [12]. Scholars' definition of tourism destination image not only focused on tourist's individual opinion, but also according to the objective situation of the destinations. By literature research, the study of tourism destination image in China were mission and practice oriented, scholars tended to explore image from destination perspective. However, some scholars focused on people’s perspective, 
they mainly discussed the influence of perception image, the formation of perception, marketing management and empirical studies of perception image.

Song (2000) came up with the idea that tourism destination image had perception and non-perception two parts, and then he analyzed the influence on the perception and non-perception to tourists [13]. Zhang, Lu and Zhang (2006) found that tourism destination image followed the law of diminishing space [14]. Liu, Wu and Xiao (2006) discovered that the order of different tourist destinations would affect tourists' perception [15]. Zhou (2007) proved that the perception of destination image was affected by the watching way, cultural environment, medium and demographic feature [16]. Liu et al. (2015) studied the influencing factors of destination image, from high to low, they were tourism facilities, atmosphere, environment, service price and service, and they took empirical research by the domestic tourists traveling in Beijing during National Day [17]. Scholars in China are apt to consider it is doubtful of explaining tourism destination image from subjective perspective, because people's perception to one destination also need to base on objective situation [18].

\subsection{Content Analysis in Tourism Study}

Content analysis method arises at the beginning of the 20th century, which was first used in the press. American famous communication expert Berenson (1952) defined content analysis method as a research method which was objective, systematical and quantificational described distinct communicate content. After that, it was widely used in journalism, communication, library-information, psychology and other social sciences [19].

Content analysis can be divided into three types, they are interpretation content analysis, experiment content analysis and computer-assisted content analysis [20]. Interpretation content analysis is a method that researchers read, understand and explain the content the writers tended to convey. Experiment content analysis is a method combines qualitative and quantitative researches. Qualitative content analysis is like cloze tests which describes and ratiocinates the connection and structure of each concept, while quantitative content analysis mainly analyses the words frequency. Recently, the development of computer makes the computer-assisted content analysis has developed fast.

When searching for literature, we found that content analysis used in tourism study mainly was tourism destination image, tourism destination marketing, tourists' experience, tourists' motivation, tourism concept and so on. Content analysis using in tourism destination image focused on the perception of tourism to one destination (Stepchenkova and Morrison, 2006) [21], the comparison between different mediums of one destination (Stepchenkova and Zhan, 2013) [22] and the formation of tourism destination image (Llodrà-Riera et al., 2015) [23]. The content of content analysis was tourism official websites, user-generated content websites, newspaper, advertisement, blogs and government official documents.

In China, content analysis using in tourism study was after 2000, and the quantity was relatively few. The main study was about the definition of concept, destination image, tourists' motivation, the satisfaction of tourists and tourism marketing (He, 2012) [24]. The object of content analysis was online travels, online communities, sina microblogs, photos, destination official websites and blogs. Most of the research analysed the texts, and based on the internet, by using computer-assisted technology, such as Nvivo, Spss and Rost.

\section{Methodology}

\subsection{Select Online Travels}

We chose www.mafengwo.cn to be the travels analysis website, the reasons are listed as follows:

Firstly, during our research period, www.mafengwo.cn was often ranking first in Alexa among the specialized travels websites in China. Secondly, www.mafengwo.cn was a website providing user-generated content for the users, and the website has accumulated a large number of users, the quality of travels they published about Guangzhou were up to 5000. Finally, comparing with Ctrip and other travels websites, the quality of travels about Guangzhou in www.mafengwo.cn was highest. As a result, we chose www.mafengwo.cn to be the travels analysis website.

We sorted the travels about Guangzhou according to the newest time (the expiration date was April 11, 2015), we got 891 travels, then we numbered and analyzed them. The release time of them were from August 31, 2014 to April 11, 2015. After selecting, we finally got 241 travels. The rules we selected the travels were listed as follows: Firstly, got rid of travels which were all photos without words. Secondly, got rid of travels without tra- 
velling places or features of the places. Thirdly, got rid of unfinished travels. And then got rid of travels which were not narration. Finally, got rid of travels besides Guangzhou including other cities.

\subsection{Process the Online Travels}

The rules we process these 241 travels were as followed: Firstly, deleted the pictures and videos in the travels, we just analyzed the words. Secondly, in order to make sure the expression and be convenient to count, we substituted Xiaomanyao for Cantonese Tower, substituted Jiulong Lake Park for European Small Town and so on. Thirdly, in order to guarantee the statistic scientificity, we substituted the words which could be count repeated, such as we substituted Pearl Night for Pearl River Night Cruise, preventing the double count of Peal River. Afte processing of the 241 travels, we got about 750 thousand words, the average words of each travels were about 3100 .

\subsection{Research Software}

This paper used Rost CM6.0 to analyze the travels content. Rost was designed by Dr. Shen and his Rost Virtual Learning Team, who worked in Wuhan University. This software is specialized in Chinese content analysis, which can capture the website in real time and convert to txt to save. What's more, it can count the words frequency, analyze social network, do semantic analysis and emotion analysis. Rost CM6.0 is popular, the users are all over the world, including Cambridge University, Loughborough University, Texas A\&M University, Peking University, Sun Yat-sen University et al.

\subsection{Content Analysis Category}

The classification of perception tourism destination image is based on Baloglu and Mc Cleary (1999), which are cognitive image and affective image. The cognitive image including five factors, which Beerli and Martin summarized in 2004, namely natural and cultural resource, tourism and leisure facility, atmosphere, social situation and environment and beach [25].

Russel and his colleagues (1980) pointed out that affective quality could be measured according to a two-dimensional bipolar space model, which could be defined by eight variables (Figure 1): pleasant, exciting, arousing, distressing, unpleasant, gloomy, sleepy and relaxing, but only two of the scales (pleasant-unpleasant and arousing-sleepy) were proved theoretically needed to represent affective space and images [26].

The content analysis category is three parts, the first part was basic information of the travels writers, including the amount of Guangzhou and non-Guangzhou tourists, male and female tourists. The second part was the perception tourism destination image, we based on Baloglu and McCleary (1999)'s classification, which destination image was divided into cognitive image and affective image, and cognitive image was divided into five factors according to Beerli and Martin, but in accordance with the content of travels of Guangzhou, we adjusted the five factors, so we just analyzed natural and cultural resources, tourism facilities and services, social environment and atmosphere. The affective image was based on Russel and his colleagues' (1980) two-dimensional bipolar space circumplex model. And the last part was comparing the image of Guangzhou positioning in the

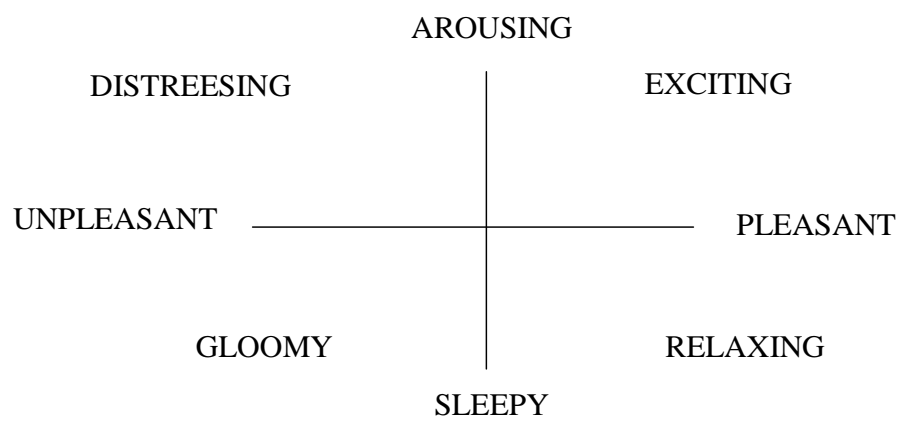

Source: Russel, J. A., and G. Pratt (1980) a Description of Affective Quality Attributed to Environment. Journal of Personality and Social Psychology, 38, 311-322.

Figure 1. Two-dimensional representation of a circumplex model of the affective quality (appraisal) attributed to places/environments. 
literature with the online travels image.

\section{Research Analysis}

\subsection{The Basic Information of Writers of Selected Travels}

We have chosen 241 travels, in which most of the writers were non-Guangzhou, and the travels of non-Guangzhou to Guangzhou ratio was 1.87 to 1 . Moreover, the number of words of non-Guangzhou was almost twice the Guangzhou in total. The mainly reason was that to Guangzhou travelers, it was daily leisure activities, so the stay time was short, and the scenic spot was often one or two. As a result, the number of words was relatively fewer. According to writers' gender, the number of female to male ratio was 2.39 to 1 , almost the same as 891 travels. Generally speaking, comparing to males, females wrote more words, their travels were longer than males'. It was obvious that female tourists tended to share their tourism experience by travels and convey more content. After reading 241 travels, we found that most of the writers were choosing independent travel, instead of package tour, and the stay time was 3 - 5 days with their families or friends. The basic information about the travels writers sees Table 1.

\subsection{The Cognitive Image of Selected Travels}

\subsubsection{Natural and Cultural Resources}

We have extracted 50 first high-frequency words, and found that cultural resources were more than natural resources, which coincided with the situation of Guangzhou tourism resources. Chimelong, Cantonese Tower and Shameen were mentioned a lot by the writers in travels. Chimelong became famous not only it was most welcomed artificial theme park, but also two TV shows called Dad Where Shall We Go and Wonderful Friends were taken films here by Hunan Satellite. With the broadcast of these shows, they expanded the popularity of Chimelong, the phrases Dad where shall we go have been mentioned 40 times, and one travel note wrote, "I have heard that Chimelong is an interesting place, after watching the show, her dad made a decision to go for a real Dad Where Shall We Go. YCQ is very excited when hearing we would go to the show place" (No. 0724). Cantonese tower is a landmark building in Guangzhou, which represents new appearance of Guangzhou. Shameen building group is western-style houses, which also attracts tourists' attention. According to The Classification, Investigation and Evaluation of Tourism Resource (GB/T18972-2003), we classified the 50 high-frequency words, and saw Table 2.

According to Table 2, we found that tourists preferred to visit cultural resources in Guangzhou, and mainly visited the synthetic human cultural tourism sites, the second one was living places and communities. In synthetic human cultural tourism sites, they preferred the recreation and amusement resorts, and Chimelong Holiday Resort was most popular. Garden recreational areas were also mentioned a lot. Universities became a tourism resource, such as South China Agricultural University (SCAU). In March, the cherry blossom festival had attracted many people, and one travel note had mentioned that, "in the middle of March, it's the best time to appreciate the cherry. With the popularity of SCAU in Guangzhou, the flow of people is very large, but if you want to appreciate the flowers, you'd better not to choose the weekend” (No. 0068). The proportion of park was large, Yuexiu Park was famous, and when mentioning Yuexiu Park, Five-Rams Stone Sculpture attracted people's attention, because it was landmark building there. The frequency of Five-Rams Stone Sculpture was 126, which illustrated the image of ram city went deep in people's mind. In living places and communities, streets and buildings with Lingnan style got much concern, such as Shangxiajiu Pedestrian Street, Beijing Road, and Xiguan Mansion.

Table1. The basic information of 241 travels.

\begin{tabular}{ccccc}
\hline Writers & Classification & Numbers & Words & Average words of per travels \\
\hline \multirow{2}{*}{ According to the resident place } & Guangzhou & 84 & 158,777 & 590 \\
& Non-Guangzhou & 157 & 593,320 & 204,751 \\
According to the gender & Male & Female & 170 & 547,112 \\
Total & & 241 & 752,097 & 3121 \\
\hline
\end{tabular}


Table 2. The classification of 50 high-frequency words.

\begin{tabular}{|c|c|c|c|c|c|c|}
\hline & Main class & Sub class & Fundamental class & Concrete content & Frequency & Total \\
\hline \multirow{2}{*}{$\begin{array}{c}\text { Natural } \\
\text { resources }\end{array}$} & $\begin{array}{l}\text { A, Land } \\
\text { scenery }\end{array}$ & $\begin{array}{l}\text { AA, Synthetic natural } \\
\text { tourism areas }\end{array}$ & $\begin{array}{l}\text { AAA, Mountain tourism } \\
\text { areas }\end{array}$ & $\begin{array}{l}\text { Baiyun Moutain, Huolu Moutain, and } \\
\text { Baishuizai Scenic Spots }\end{array}$ & 372 & 372 \\
\hline & $\begin{array}{l}\text { B, Water area } \\
\text { landscape }\end{array}$ & BA, Stream segments & $\begin{array}{l}\text { BAA, Sightseeing and } \\
\text { recreational segments }\end{array}$ & Pearl River & 400 & 400 \\
\hline \multirow{17}{*}{$\begin{array}{l}\text { Cultural } \\
\text { resources }\end{array}$} & \multirow{17}{*}{$\begin{array}{l}\text { F, Architecture } \\
\text { and facilities }\end{array}$} & \multirow{8}{*}{$\begin{array}{l}\text { FA, Synthetic human } \\
\text { cultural tourism sites }\end{array}$} & $\begin{array}{c}\text { FAA, } \\
\text { Test sites for teaching and } \\
\text { scientific research }\end{array}$ & $\begin{array}{l}\text { The Huangpu Military Academy, Sun } \\
\text { Yat-sen University, South China } \\
\text { Agricultural University, and } \\
\text { Guangzhou Higher Education } \\
\text { Mega Center }\end{array}$ & 517 & \multirow{8}{*}{5938} \\
\hline & & & $\begin{array}{l}\text { FAB, } \\
\text { The recreation and } \\
\text { amusement resorts }\end{array}$ & $\begin{array}{l}\text { Chimelong Holiday Resort and } \\
\text { Jiulong Lake Resort }\end{array}$ & 1703 & \\
\hline & & & $\begin{array}{l}\text { FAC, Religion and } \\
\text { sacrificial places }\end{array}$ & $\begin{array}{l}\text { Shishi Sacred Heart Cathedral and } \\
\text { Guangxiao Temple }\end{array}$ & 549 & \\
\hline & & & $\begin{array}{c}\text { FAD, } \\
\text { Garden recreational areas }\end{array}$ & $\begin{array}{l}\text { Baomo Garden, Lingnan Impression, } \\
\text { Nanyue Garden, Yunxi Ecological } \\
\text { Park, Shimen National Forest Park } \\
\text { and Yuexiu Park }\end{array}$ & 1224 & \\
\hline & & & $\begin{array}{c}\text { FAE, } \\
\text { Places of cultural activities }\end{array}$ & $\begin{array}{l}\text { Guangdong Provincial Museum, } \\
\text { Guangzhou Museum, Fangsuo } \\
\text { Library and Guangzhou Library }\end{array}$ & 297 & \\
\hline & & & $\begin{array}{c}\text { FAG, } \\
\text { Places of social and trade } \\
\text { activities }\end{array}$ & Taikoo Hui and Tee Mall & 135 & \\
\hline & & & $\begin{array}{l}\text { FAH, Exhibited places of } \\
\text { animals and plants }\end{array}$ & $\begin{array}{l}\text { South China Botanical Garden and } \\
\text { Millions of Sunflowers Garden }\end{array}$ & 326 & \\
\hline & & & FAK, Scenery enjoy spots & Cantonese Tower & 1187 & \\
\hline & & $\begin{array}{l}\text { FB, Single places for } \\
\text { cultural or sports } \\
\text { activities }\end{array}$ & $\begin{array}{c}\text { FBC, } \\
\text { Demo rooms }\end{array}$ & Haixinsha Island & 209 & 209 \\
\hline & & $\begin{array}{l}\text { FC, Landscape and } \\
\text { appertaining } \\
\text { architectures }\end{array}$ & $\begin{array}{l}\text { FCI, } \\
\text { Square }\end{array}$ & Huacheng Square and Haizhu Square & 255 & 255 \\
\hline & & \multirow{4}{*}{$\begin{array}{l}\text { FD, } \\
\text { Living Places and } \\
\text { Communities }\end{array}$} & FDB, Characteristic streets & $\begin{array}{l}\text { Shameen, Shangxiajiu, Beijing Road, } \\
\text { Dongshan Western-style Houses, } \\
\text { Xiguan Mansion and Litch Bay }\end{array}$ & 2869 & \multirow[t]{4}{*}{4561} \\
\hline & & & $\begin{array}{l}\text { FDC, Characteristic } \\
\text { comunities }\end{array}$ & $\begin{array}{l}\text { Redtory, Xiaozhou Village, Shawan } \\
\text { Ancient Town and Xitou Village }\end{array}$ & 757 & \\
\hline & & & $\begin{array}{c}\text { FDD, Celebrity residence } \\
\text { and historic } \\
\text { commemorative buildings }\end{array}$ & $\begin{array}{l}\text { Liugengtang, Lin Zexu Memorial } \\
\text { Hall, Sun Yat-sen Memorial Hall and } \\
\text { Yuyin Garden }\end{array}$ & 265 & \\
\hline & & & FDE, Academies & Chen Clan Temple & 670 & \\
\hline & & FE, Burial places & FEB, Tombs(group) & Tomb of the Nanyue King & 163 & 163 \\
\hline & & $\begin{array}{l}\text { FF, Transportation } \\
\text { buildings }\end{array}$ & FFC, Ferry and dock & $\begin{array}{l}\text { Tianzi Marina, the Ancient Huangpu } \\
\text { Harbor and Taigu Marina }\end{array}$ & 109 & 109 \\
\hline & & FG, Sections of dyke & FGD, Sections of dyke & The $19^{\text {th }}$ Chung & 36 & 36 \\
\hline
\end{tabular}

\subsubsection{Tourism Facilities and Service}

\section{1) Catering Analysis}

Among the catering words, morning tea (zaocha), dessert and Taotaoju (a restaurant) were the first-threementioned words. Morning tea was a special breakfast activities in Lingnan area, which has become one of the activities tourists should experience. One travel note said, "In the early morning, we begin our morning tea, it is an activities must take in Guangzhou, to Cantonese, ordering a bottle of tea, watching newspaper and chatting 
with each other are everywhere in restaurants” (No. 0572). When talking about desserts, Nanxin Milk Dessert was very famous. Taotaoju was one of the time-honored brand shops in Guangzhou, so it also became a special catering to tourists. We analyzed the 50 high-frequency catering words and sorted them out (see Table 3).

According to the 50 high-frequency catering words, we found that tourists mainly chose the time-honored brand shops, and they mainly chose the famous food, for example, the fish skin and Tingzai Porridge of Chentianji, the double-skin milk and beef three star of Nanxin Milk Dessert. The word delicious food has been mentioned up to 302 times and foodie up to 94, that's to say, several number of tourists considered themselves as foodies, the trip to Guangzhou was a trip of delicious food. Some title of the travels have expressed their wish for delicious food in Guangzhou, such as Trip of Delicious Food in Guangzhou in June 1 (No. 0572), Trip of Delicious Food in Guangzhou, I am a Foodie, just Go (No. 0393). There were several time-honored brand in Baohua Road, such as Baohua Noodle House, Chentianji, Shunji, Lin Heung Lau, Nanxin Milk Dessert and so on, therefore, it attracted lots of tourists.

\section{2) Accommodation Quality}

Generally speaking, tourists gave positive evaluation to accommodation in Guangzhou, based on the content of the travels. Hotel has been mention for 967 times, but not all the travel notes have evaluation to hotel, by analyzing the content, we found that Chimelong Holiday Resort was the most mentioned scenic spots, so Chimelong Hotel was also mentioned a lot. A part of families visiting Chimelong Holiday Resort chose to live in Chimelong Hotel, one travel note said, "we lived in Chimelong Hotel, comparing to other hotels, it was expensive, when we booked this hotel, it was about 800yuan per night (not including breakfast and tickets), but the environment was good and safe, moreover, it was very convenient to Chimelong Park” (No. 0556). However, most of the tourists considered the fare of Chimelong Hotel was high, one travel note wrote that, they couldn't afford the room fare of Chimelong Hotel (No. 0194). Another travel note mentioned, "it was said that the environment of Chimelong Hotel was excellent, but we couldn’t accept the price, searching for the hotels around, we finally chose the Atlan Hotel" (No. 0152). Then we found that seldom of them chose hostels, but the young tourists would choose the economy hotels because of the convenient transportation and low price. The evaluation of economic hotels was different from different hotels, but most of them thought it was lower price and convenient. One travel note wrote that there were many economic hotels here, such as 7 days and home inn, average price of them was 300 yuan, which he could accept, and it was convenient to go to subway, shopping and eating (No. 0153).

\section{3) Transportation}

From Table 4, we found that the main means of transportation tourists taken to Guangzhou were trains and air

Table 3. The classification of the 50 High-frequency catering words.

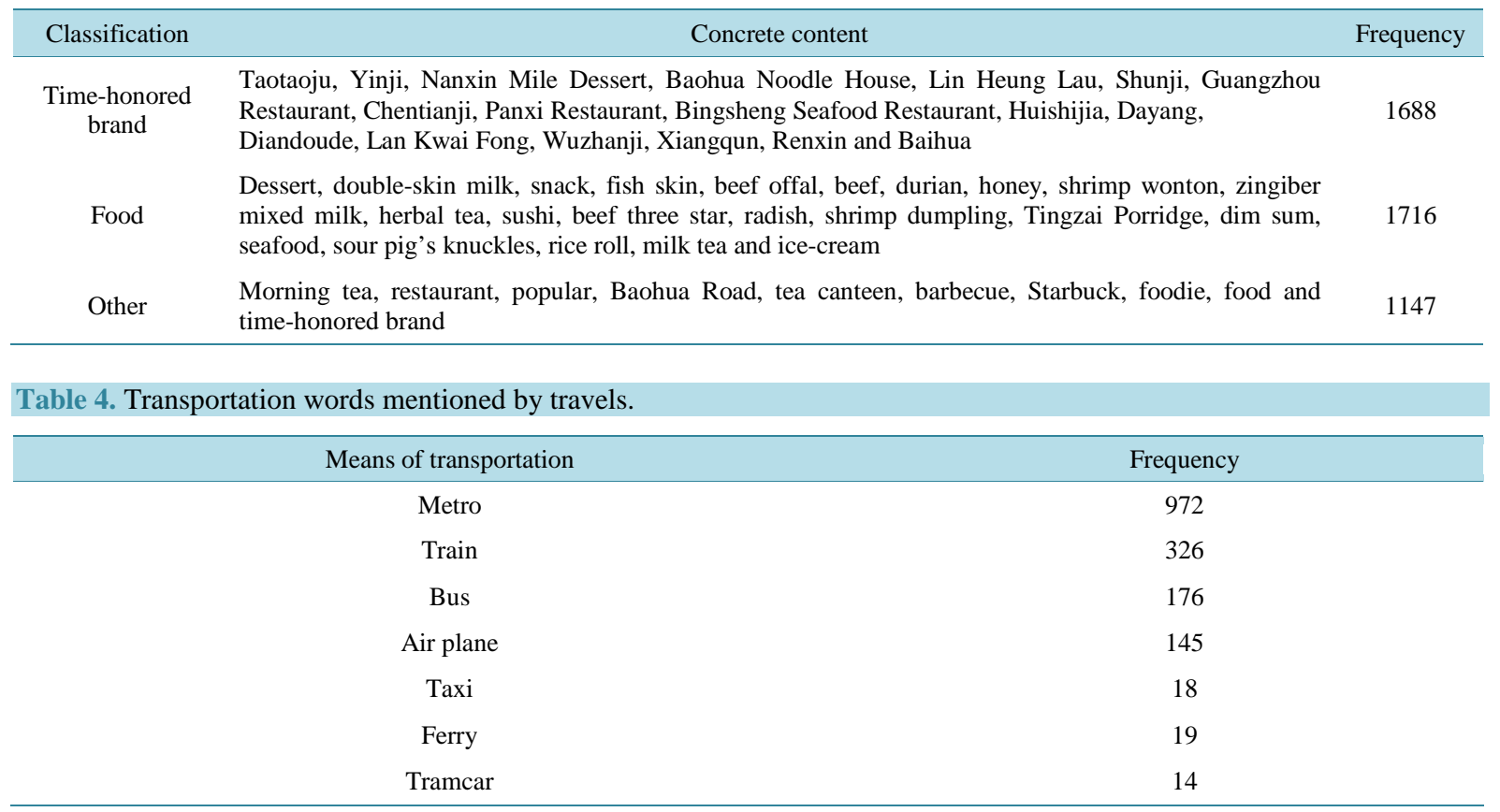


planes, and the in city transportation was metro, one travel note mentioned that, the coverage of metro in Guangzhou was very large, which was not less than Shanghai and Beijing. As a result, if you need to plan a long trip in Guangzhou, you can take metros as a main transportation (No. 0563). Besides, buses were also the main transportation in Guangzhou, "bus in Guangzhou is also very convenient, we have suffered heavy rain and we couldn't take a taxi but take a bus” (No. 0149), one travel note said. However, most evaluation of taxi was negative, they thought taxis in Guangzhou needed to wait for a long time, sometimes you even needed to rush to get a taxi, and the drivers had the suspicion to cheat the customers. One travel note said, "we have made a decision to spend much money to take a taxi to go back hotel, but after arriving, we haven't seen a taxi” (No. 0726), another travel note said, “we have been waiting for about half an hour, but haven’t see a taxi, it's very fewer, moreover we can't get a taxi because of too much people waiting here” (No. 0530).Tramcars served as a means of transport with sightseeing and communication function were run in the end of 2014, which got much attention. To tourists, it was a sightseeing transportation. "When the tramcar gets in the station, it looks like a famous star, people put up their phones and cameras to take photos for the tramcar (No. 0415),”one travel note said.

\subsubsection{Leisure and Recreational Activities}

Seldom of tourists talked about the leisure and recreational activities in Guangzhou, and their recreational activities were shopping, taking tramcars, taking Cantonese tower sightseeing elevator and so on. Shangxiajiu Pedestrian Street and Beijing Road were good places for shopping, goods were cheap, "Shopping in Shangxiajiu is very convenient (No. 0135)” one travel note said. Secondly, some malls, such as Teemall, One Link Walk and Grand Buy, were also good places for shopping. Tourists were generally positive when talking about shopping, “There are lots of brands in Teemall and One Link Walk, shopping here is your best choice (No. 0420)"one travel note said. Shopping in night market was a characteristic and recreational activities in Guangzhou, "In the evening, the light on the road and the neon light of shops are light up, which brings you get into a splendid night scenery, it is so charming (No. 0420)” one travel note said.

\subsubsection{Social Environment}

The analysis of social environment was mainly from three aspects, namely the friendliness of local residents, the appearance of the city and the obstacle of localism. When talking about the friendliness of local people, some of them said, "The Cantonese entertain friends very well. (No. 0531)” one travel note said. Another travel note said, “Guangzhou is a good place, people here are hospitable (No. 0792)” Tourists thought Guangzhou was a large and prosperous city, "You can find out all the features of international metropolitan, which are tall buildings, wide and neat streets and people everywhere (No. 0665)" one travel note wrote. "Look at the shops on the both side of the pedestrian streets, think about the flourishing from millennium to now, such a feeling of traversing occurred me”(No. 0320) a travel note said. When talking about the obstacles of localism, the main localism of Guangzhou was Cantonese, which became a feature as well as an obstacle. One tourist said, "Buses here are broadcast mandarin and Cantonese, when it broadcast Cantonese, I have no idea what it is talking about, but this makes me feel I have been to south China, and realized Lingnan culture (No. 0028).”

\subsection{The Affective Image of Selected Travels}

From Table 5, we knew that most of the tourists gave positive evaluation to their trip. To tourists, the trip to Guangzhou was pleasant and arousing, scholars have pointed out that the essence of tourism was enjoyable experience [27] or poetic dwelling [28], as a result, the purpose of tourism was for happiness. "The time of happiness is always short (No. 0028)" one travel note said. Another said, "The staff along the way waved for us, what a happy journey” (No. 0187). However, some evaluations of Guangzhou were unpleasant and sleepy, the main

Table 5. Analysis of emotional words of travels.

\begin{tabular}{clc}
\hline Dimensionality & \multicolumn{1}{c}{ Concrete content } & Frequency \\
\hline Pleasant & Happy, pleasant, interested, enchanted, satisfied, joyful... & 789 \\
Unpleasant & Unhappy, unpleasant, disappointed, frustrated... & 354 \\
Arousing & Aroused, excited, surprised, amazed, surprised... \\
Sleepy & Bored, sleepy, drowsy... \\
\hline
\end{tabular}


reasons were that tourists were looking forward to the attractions and catering, but the experience was not perceived as high as expectation, and therefore they were disappointed. "The location is not convenient, it is far away from the metro station... it is the most disappointing station of the trip (No. 0324)"one tourist said. "The taste is just so so, it is not tasty as expectation, a little bit disappointed" (No. 0371) "After entering the interstellar battle, I feel so bored, it is just travel to 3D space, I almost sleep (No. 0656) another two travels wrote down.

As a result, most of the affective appraisal which tourists to Guangzhou is positive, while the negative appraisal is because of the gap of expectation and perception to attractions and catering.

\subsection{Analysis of Guangzhou Destination Image}

We searched for the literature about Guangzhou destination image in CNKI, and got 3 papers about Guangzhou image positioning (saw Table 6). The four authors positioned Guangzhou destination image from different aspects, and we combine the position with the travels content, than we analyzed the frequency of Guangzhou destination image words (saw Table 7).

Combining Table 6 and Table 7, we found that tourists mentioned delicious food, Lingnan and Ram City a lot in their travels, Lingnan architectures and delicious food are two characteristic of Guangzhou, and the image of ram city impressed tourist most. While history and culture are seldom mentioned by tourists, which illustrated that tourists paid more attention to modern tourist attractions. Therefore, delicious food, Lingnan and Ran city are the prominent perceived by the tourists in their travels.

\section{Conclusions}

By analyzing the travels of Guangzhou in www.mafengwo.cn, we explored the tourism destination image perceived by the tourists. We analyzed the tourism destination image from two aspects, namely cognitive image and affective image. The conclusions we got were listed as follows.

Firstly, the writers of the travels were female and non-Guangzhou, they usually traveled with friends and relatives for 3 - 5 days and chose independent travel.

Secondly, in the cognitive image analysis, they preferred recreation and amusement resorts of synthetic human cultural tourism sites. Moreover, universities also became tourist attractions. In living places and communities, tourists paid attention to streets with Lingnan style. Morning tea, dessert and Taotaoju were mentioned first three words, and tourists would go to time-honored brand shops and ordered the recommended food. When talking about the accommodation in Guangzhou, most of them gave positive evaluation to accommodation, tourists who visited Chimelong Holiday Resort would choose Chimelong Hotel, but they considered the fare of Chimelong Hotel was high. Seldom of tourists would choose hostels, the young preferred economic hotels because of the convenient transport and low price. The main means tourists chose to get to Guangzhou were trains

Table 6. Literature of the positioning of Guangzhou destination image.

\begin{tabular}{ccc}
\hline Author & Year & The positioning of Guangzhou image \\
\hline Yu & 1998 & Ecology city, the door of south China and tourism center of Lingnan landscape culture \\
Huang and Zhang & 2007 & International metropolis and famous cultural city \\
$\mathrm{Hu}$ & 2009 & Lingnan and millennium city, food paradise and popularity \\
\hline
\end{tabular}

Table 7. The frequency of Guangzhou destination image.

\begin{tabular}{ccc}
\hline Guangzhou Image & Frequency \\
\hline Delicious Food & 302 \\
Lingnan & 236 \\
Ram City & 126 \\
Flower City & 40 \\
History and Culture city & Sui City & 9 \\
\hline
\end{tabular}


and air planes, metros were intracity transport, however, the evaluation of taxi was negative. Most evaluation of leisure and recreational activities were positive, they considered Shangxiajiu and Beijing road were good places for shopping, goods here were cheap, and the malls were also suitable for shopping. Shopping in night market, taking tramcar were the leisure and recreational activities as well. When talking about the social environment, tourists thought local residents were friendly and enthusiastic, and Guangzhou was a large and prosperous city. Cantonese was characteristic of Guangzhou as well as the communication barrier.

Thirdly, most affective evaluation of Guangzhou was positive and the negative evaluation was because of the gap of expectation and perception on tourism attractions and food.

Finally, by analyzing the positioning image of Guangzhou suggested by the scholars and the frequency of Guangzhou destination image of the travels, we knew that tourists agreed that Guangzhou was a metropolis with the feature of Lingnan culture, and Ram City impressed tourists most, besides Guangzhou was a paradise of delicious food.

\section{Acknowledgements}

This study was supported by Jinan University's Scientific Research Creativeness Cultivation Project for Outstanding Undergraduates Recommended for Postgraduate Study in 2014.

\section{References}

[1] Lei, Y. (2013) The Process and Comparison of Destination Image in China and Abroad in Latest Five Years. Journal of Shijiazhuang University, 6, 67-71.

[2] Hunt, J.D. (1975) Image as a Factor in Tourism Development. Journal of Travel Research, 13, 1-7. http://dx.doi.org/10.1177/004728757501300301

[3] Crompton, J.L. (1979) An Assessment of the Image of Mexico as a Vacation Destination and the Influence of Geographical Location upon the Image. Journal of Travel Research, 18, 18-23. http://dx.doi.org/10.1177/004728757901700404

[4] Echtner, C. and Ritchie, J.R.B. (1993) The Measurement of Destination Image: An Empirical Assessment. Journal of Travel Research, 24, 3-13. http://dx.doi.org/10.1177/004728759303100402

[5] Kotler, P. and Barich, H. (1991) A Framework for Marketing Image Marketing Image Management. Sloan Management Review, 32, 94-104.

[6] Nuria, G.E. and Jose, A.D.B. (2005) The Social Construction of the Image of Girona: A Methodological Approach. Tourism Management, 35, 402-426.

[7] Bramwell, B. and Rawding, L. (1996) Tourism Marketing Images of Industrial Cities. Annals of Tourism Research, 23, 201-221. http://dx.doi.org/10.1016/0160-7383(95)00061-5

[8] Baloglu, S. and McCleary, K.W. (1999) A Model of Destination Image Formation. Annals of Tourism Research, 26, 868-897. http://dx.doi.org/10.1016/S0160-7383(99)00030-4

[9] Grosspietsch, M. (2006) Perceived and Projected Images of Rwanda: Visitor and International Tour Operator Perspectives. Tourism Management, 27, 225-234. http://dx.doi.org/10.1016/j.tourman.2004.08.005

[10] Selby, M. and Nigel, J.M. (1996) Reconstruing Place Image: A Case Study of Its Role in Destination Market Research. Tourism Management, 17, 287-294. http://dx.doi.org/10.1016/0261-5177(96)00020-9

[11] Qiu, Y.M. (1986) Analysis the Tourism Image of China. Economy Problem, 8, 56-57.

[12] Li, L.L. (1999) Tourism Destination Image Planning: Theory and Practice. Guangdong Tourism Publishing Company, Guangzhou.

[13] Song, Z.H. (2000) Study on Tourism Destination Image from Tourists’ Aspect. Tourism Tribune, 15, 63-67.

[14] Zhang, H.M, Lu, L. and Zhang, J.H. (2006) The Influence of an Analysis of the Perceived Distance on Tourism Destination Image. Human Geography, 5, 25-30.

[15] Liu, R.W., Wu, D.T., Xiao, X. and Lei, Y.Z. (2006) The Research on the Effect That Time Sequence of Tourists Apperceiving Destination Image Has on Destination Image Apperceiving of Tourists. Economic Geography, 1, 145-150.

[16] Zhou, J. (2007) Tourism Perceiving Image and Creation Tourist Destination's Image. Journal of Gulin Institute of Tourism, 3, 353-356.

[17] Liu, Z.X, Ma, Y.F., Li, S., Niu, Y.L. and Wei, T. (2015) Evaluation on the Factors Influencing the Tourism Image of Beijing Based on Tourists' Cognition and Perception. Journal of Arid Land Resources and Environment, 29, 203-208.

[18] Wang, L., Liu, H.T. and Zhao, X.P. (1999) Research on the Definition of Tourism Destination Image. Journal of Xi'an 
Jiaotong University (Social Sciences), 19, 25-27.

[19] Bo, W. (1997) Study on the Method of Content Analysis. Chinese Journal of Journalism \& Communication, 4, 56-60, 69.

[20] Qiu, J.P. and Zou, F. (2004) Research about Content Analysis Method. Journal of Library Science in China, 2, 14-19.

[21] Stepchenkova, S. and Morrison, A.M. (2006) The Destination Image of Russia: From the Online Induced Perspective. Tourism Management, 27, 943-956. http://dx.doi.org/10.1016/j.tourman.2005.10.021

[22] Stepchenkova, S. and Zhan, F.Z. (2013) Visual Destination Image of Peru: Comparative Content Analysis of DMO and User-Generated Photography. Tourism Management, 36, 590-601. http://dx.doi.org/10.1016/j.tourman.2012.08.006

[23] Riera, I.L., Ruiz, M.P.M., Zarco, A.I.J. and Yusta, A.I. (2015) A Multidimensional Analysis of the Information Sources Construct and Its Relevance for Destination Image Formation. Tourism Management, 48, 319-328. http://dx.doi.org/10.1016/j.tourman.2014.11.012

[24] He, Y. and Yang, X.X. (2012) Literature Review and Application of Content Analysis Method in Tourism Research in China. Journal of Southwest Agricultural University (Social Science Edition), 10, 6-12.

[25] Beerli, A. and Martin, J.D. (2004) Factors Influencing Destination Image. Annals of Tourism Research, 31, 657-681. http://dx.doi.org/10.1016/j.annals.2004.01.010

[26] Russel, J.A. and Pratt, G. (1980) A Description of Affective Quality Attributed to Environment. Journal of Personality and Social Psychology, 38, 311-322. http://dx.doi.org/10.1037/0022-3514.38.2.311

[27] Yang, Z.Z. (2014) On the Essence of Tourism. Tourism Tribune, 29, 13-21.

[28] Xie,Y.J. (1998) On the Nature and Features of Tourism. Tourism Tribune, 13, 41-44, 63. 